(2) CrossMark

Cite this: RSC Adv., 2016, 6, 58363

DOI: 10.1039/c6ra90054b

www.rsc.org/advances

\title{
Correction: Amyloid fibrils as rapid and efficient nano-biosorbents for removal of dye pollutants
}

\author{
Wai-Hong Leung, Wai-Hung Lo and Pak-Ho Chan*
}

Correction for 'Amyloid fibrils as rapid and efficient nano-biosorbents for removal of dye pollutants' by Wai-Hong Leung et al., RSC Adv., 2015, 5, 90022-90030.

The authors regret that on a number of occasions in the original article, the variables ' $q_{t}$ ' and ' $C_{t}$ ' were incorrectly written as ' $q_{\mathrm{e}}$ ' and ' $C$ ' ', respectively. Formal definitions for $q_{t}$ and $C_{t}$ were also missing. As a result, a number of sentences from the original article are revised as follows.

On page 90024, the sentence beginning "The adsorption capacity $\left(q_{\mathrm{e}}\right)$ at each time interval..." should instead read "The adsorption capacity at each time interval $\left(q_{t}\right)$ was determined as described above [eqn (1), with $q_{\mathrm{e}}$ and $C_{\mathrm{e}}$ replaced by $q_{t}$ (the adsorption capacity at the time interval $t$ ) and $C_{t}$ (the dye concentration at the time interval $t$ after adsorption) respectively]."

On page 90027, the sentence beginning "Fig. 6 shows the adsorption capacity..." and the sentence immediately following should instead read "Fig. 6 shows the adsorption capacity $\left(q_{t}\right)$ of lysozyme nanofibers with Reactive Black 5 at different time intervals. Surprisingly, lysozyme nanofibers adsorb Reactive Black 5 very quickly ( $\mathrm{pH} 3.0$ ); the $q_{t}$ value reaches $155 \mathrm{mg} \mathrm{g}^{-1}$ at $t=4$ min and then remains steady over the time course $(t=1-180$ min, Fig. 6)."

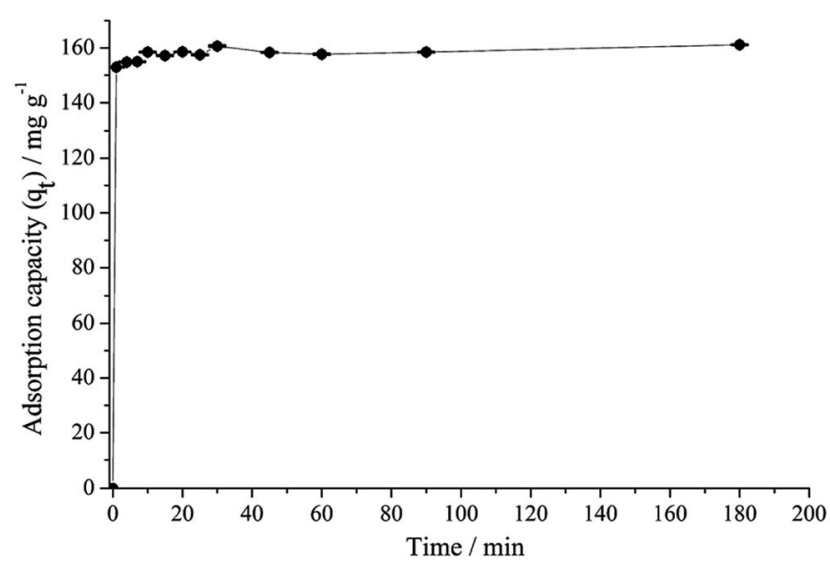

Fig. 6 Kinetic profile of the adsorption of Reactive Black 5 by lysozyme nanofibers. Solution conditions of Reactive Black 5 : dye concentration = $109 \mathrm{mg} \mathrm{L}^{-1}(109 \mathrm{mM}$ ); volume $=40.0 \mathrm{~mL} ; \mathrm{pH}$ 3.0. Lysozyme nanofibers (24 mg) were added to the Reactive Black 5 solution for dye adsorption. The adsorption capacities of lysozyme nanofibers at different time intervals were determined by absorbance measurements on the dye solution before and after dye adsorption. Triplicate measurements were conducted at each time interval.

On page 90027, the sentence beginning "In this case, lysozyme nanofibers can reach..." should instead read "In this case, lysozyme nanofibers can reach their adsorption equilibrium $\left(q_{t}=101 \mathrm{mg} \mathrm{g}^{-1}\right)$ at $\mathrm{t}=4 \mathrm{~min}$ (Fig. S4 in the ESI $\dagger$ )."

On page 90027, the sentence beginning "Under this condition, lysozyme nanofibers..." should instead read "Under this condition, lysozyme nanofibers can reach their adsorption equilibrium $\left(q_{t}=86 \mathrm{mg} \mathrm{g}^{-1}\right)$ at $t=15 \mathrm{~min}$ (Fig. S5 in the ESI)." 
Additionally, the $y$-axes of the graphs in Fig. 6 and S4 and S5 should have been labelled as "Adsorption capacity $\left(q_{t}\right) / \mathrm{mg} \mathrm{g}^{-1}$ ". A corrected version of Fig. 6 is presented herein and the ESI of the original article has been updated accordingly.

The authors also wish to add that the grant code listed in the Acknowledgements section of the article was incorrect, and is therefore corrected in the Acknowledgements section herein.

The Royal Society of Chemistry apologises for these errors and any consequent inconvenience to authors and readers.

\section{Acknowledgements}

We thank the State Key Laboratory of Chirosciences (4-BBX3) and the Research Committee of The Hong Kong Polytechnic University for support to this project. 